IZA DP No. 4225

Attitudes toward Uncertainty among the Poor:

Evidence from Rural Ethiopia

\author{
Alpaslan Akay \\ Peter Martinsson \\ Haileselassie Medhin \\ Stefan T. Trautmann
}

June 2009 


\title{
Attitudes toward Uncertainty among the Poor: Evidence from Rural Ethiopia
}

\author{
Alpaslan Akay \\ IZA and University of Gothenburg \\ Peter Martinsson \\ University of Gothenburg \\ Haileselassie Medhin \\ University of Gothenburg \\ Stefan T. Trautmann \\ TIBER and CentER, Tilburg University
}

\author{
Discussion Paper No. 4225 \\ June 2009
}

IZA

P.O. Box 7240

53072 Bonn

Germany

Phone: +49-228-3894-0

Fax: +49-228-3894-180

E-mail: iza@iza.org

\begin{abstract}
Any opinions expressed here are those of the author(s) and not those of IZA. Research published in this series may include views on policy, but the institute itself takes no institutional policy positions.

The Institute for the Study of Labor (IZA) in Bonn is a local and virtual international research center and a place of communication between science, politics and business. IZA is an independent nonprofit organization supported by Deutsche Post Foundation. The center is associated with the University of Bonn and offers a stimulating research environment through its international network, workshops and conferences, data service, project support, research visits and doctoral program. IZA engages in (i) original and internationally competitive research in all fields of labor economics, (ii) development of policy concepts, and (iii) dissemination of research results and concepts to the interested public.
\end{abstract}

IZA Discussion Papers often represent preliminary work and are circulated to encourage discussion. Citation of such a paper should account for its provisional character. A revised version may be available directly from the author. 


\section{ABSTRACT \\ Attitudes toward Uncertainty among the Poor: Evidence from Rural Ethiopia*}

We looked at risk and ambiguity attitudes among Ethiopian peasants in one of the poorest regions of the world and compared their attitudes to a standard Western university student sample elicited by the same decision task. Strong risk aversion and ambiguity aversion were found with the Ethiopian peasants. Ambiguity aversion was similar for peasants and students, but peasants were more risk averse. Testing for the effect of socio-economic variables on uncertainty attitudes showed that poor health increased both risk and ambiguity aversion.

JEL Classification: D81, C93, O12

Keywords: $\quad$ risk attitudes, ambiguity attitudes, poverty, cultural differences

Corresponding author:

Stefan T. Trautmann

Tilburg Institute for Behavioral Economics Research (TIBER)

Tilburg University

P.O. Box 90153

5000 LE Tilburg

The Netherlands

E-mail: s.t.trautmann@uvt.nl

Financial support from Sida (Swedish International Development Cooperation Agency) to the Environmental Economics Unit at the University of Gothenburg is gratefully acknowledged. 
In decision under uncertainty it has been shown that agents distinguish between prospects for which they have a clear probability assessment or feel competent because of their own expertise, and prospects for which probabilities are unknown and the agents feel less competent (Chow and Sarin, 2002; Fox and Tversky, 1995; Heath and Tversky, 1991; Viscusi and Chesson, 1999; Viscusi and Magat, 1992, Zeckhauser, 2006). The extreme case of objectively known probabilities (e.g. tails come up in a coin flip) is called risk, and the extreme case of completely unknown probabilities (e.g. rain tomorrow) is called ambiguity. Ellsberg (1961) suggested that people often prefer to bet on risky prospects instead of ambiguous prospects, even if normative theory (Savage, 1954) implies indifference. Confirming Ellsberg's conjecture, ambiguity aversion has been found in many empirical studies, also under market conditions and with monetary incentives (e.g. Halevy, 2007; Maffioletti and Schmidt, 2005; Sarin and Weber, 1993).

Most experiments on ambiguity are conducted using university students in a laboratory environment. Few studies have used non-student samples. For example, Viscusi and Chesson (1999), Maffioletti and Santoni (2005), and Cabantous (2007) show ambiguity effects for small business owners, union delegates, and insurance managers, suggesting its importance in real world decisions.

A significant number of decisions under uncertainty is also made by farmers in developing regions of the world, who, in contrast to the above mentioned groups, live near or below the poverty line. The objective of this paper is to measure attitudes toward uncertainty among small scale farmers in one of the poorest regions in the world. Knowledge of attitudes toward uncertainty is important to understand choices in traditional production activities involving well known risks, as well as to understand the uptake and adaptation of new production technologies (e.g. fertilizer) and investments (e.g. water harvesting) that involve unknown risks, leading to ambiguity. While uncertainty has been identified as an important determinant of farm technology adoption (Feder, 1980; Feder et al.,1985; Kebede, 1992), the literature does not systematically differentiate between the effect of risk aversion and ambiguity aversion.

Although ambiguity attitudes have been widely observed, there is little direct evidence in the context of development and subsistence farming. Henrich and McElreath (2002) conducted an experimental study of risk and ambiguity attitude among Chilean Mapuche small scale farmers and found no evidence for ambiguity aversion. They argued that ambiguity aversion may be driven by cultural factors, and that it does not generalize to non-western farming societies. Their explanation is consistent with the finding of a strong 
social component in ambiguity attitude (Curley et al., 1986; Trautmann et al., 2008a): pursuing ambiguous options for which little information about the risk is available is perceived as poor decision making and people seem to anticipate this and therefore avoid ambiguous risks. Such a social stigma for poor information options may not exist in nonwestern culture, reducing ambiguity aversion.

Henrich and McElreath's study shows the problems of generalizing attitudes under uncertainty from standard experimental participant pools toward culturally different groups that are of economic interest. Their findings, however, may not generalize toward other farming societies either. Two points of concern with their results are that (1) the Mapuche were unusually risk seeking for known probabilities, and (2) that there was no control experiment among a standard participant pool for the ambiguity experiment. It is conceivable that the Mapuche held especially optimistic attitudes to the chance events, possible due to friendly long-term relations with the experimenters, and therefore had optimistic views concerning the distribution of payoffs in the ambiguous task. Situations under ambiguity are even more sensitive to framing than situations of known risks (Maffioletti and Schmidt 2005; Trautmann et al. 2008b). Small differences in the decision tasks compared to studies with standard student samples at Western universities could therefore provide an obvious explanation for the observed ambiguity attitudes in the absence of a student control group.

This paper measures attitudes toward uncertainty among small scale farmers in rural Ethiopia. Our subjects differ from standard subject pools in terms of their occupation, wealth, and cultural background. The experiment used real monetary incentives with high stakes and compared the results to data from university students in the Netherlands facing the same decision tasks. The measure of ambiguity aversion controls for individual differences in risk attitudes, and we relate both risk and ambiguity attitude to socio-economic variables. The next section gives a description of the participant pool and introduces the experimental design. The results are presented in Section 2 and discussed in Section 3. The last section offers concluding remarks.

\section{Participants and experimental design}

Participants. The experiment was conducted in the village of Abraha We Atsbaha in the northern highlands of Ethiopia. The majority of the Ethiopian population resides in the highlands, where small-scale subsistence agriculture is the main economic activity. Highland agriculture in Ethiopia is characterized by population pressure, extreme land fragmentation, 
severe soil degradation, and heavy dependence on rainfall. As a result, the overall outcome is one of the lowest agricultural productivity levels in the world. During the last few decades, the number of droughts has exacerbated the problem, especially in the northern parts of the country. Abaraha We Atsbaha is one of many very poor villages in a region where most people depend on food aid programs to survive between the two annual harvests.

Our sample consisted of 92 adults with little or no formal education, and $30 \%$ of those who participated in our experiment were illiterate. Subjects were randomly selected from a list of 584 households, with either the male or female household head participating. All subjects were peasants and mainly growing wheat, maize, barley and teff. Most families also own some livestock like cattle and sheep. All participants were Christians.

Payoffs. Each participant could win up to 20 Ethiopian birr (ETB). At the time of the experiment the exchange rate was ETB $9.67=$ US\$1, and the 2007 purchasing power parity conversion rate was 6.02 for Ethiopia (Source: IMF World Economic Outlook Database, April 2008). Note that in this region, the daily wage for unskilled farm labor varies between 10-15 Birr depending on the season.

Procedure. We elicited each participant's certainty equivalents for a risky and an ambiguous prospect using a choice list. The risky prospect allowed the participant to bet on the color of a ball drawn from a bag with exactly 5 white and 5 yellow balls to win ETB 20 if the color is guessed correctly. Thus, this prospect offers a 50\% chance to win the prize. The ambiguous prospect allowed participants to bet on the color of a ball drawn from a bag with 10 balls, where each ball can be either white or yellow. The proportion of colors in the ambiguous bag is unknown. If the color is correctly predicted the participant wins ETB 20.

The two prospects are the risky and ambiguous option in the Ellsberg (1961) twocolor choice task. The ambiguous option is always at least as good as the risky option. If the participant is indifferent between betting on either color in the ambiguous option, she should be indifferent between betting on the risky option and betting on the ambiguous option. She should therefore have identical certainty equivalents for both options. If the participant believes that there are more white balls than yellow balls in the ambiguous bag, she will bet on white in the ambiguous prospect and should prefer this prospect to the risky prospect because it gives her a higher chance to win the prize, given her believes. A similar argument holds if the participant believes that there are more yellow balls in the ambiguous bag. 
To elicit participants' certainty equivalents we offer them 20 choices between a sure payoff and playing the prospect. Choices are arranged in a choice list. The sure payoff increases from ETB 1 to ETB 20. For very small sure payoffs, most participants will prefer to play the prospect, for very large sure payoffs most participants will prefer the sure cash. That is, most participants will switch from sure cash to playing the prospect at some point. We calculate the certainty equivalent as the midpoint between the lowest sure payoff for which the participant takes the sure cash and the highest sure payoff for which the participant prefers to play the prospect (see illustration in the appendix).

Note that this choice list methodology differs from the list employed by Binswanger (1980), where participants were asked to choose one prospect from a list of prospects that differed with respect to their expected payoff and variance, and the selected prospect then served as an index of risk aversion. Our method is closer to Henrich and McElreath's (2002) by directly eliciting the certainty equivalent of one prospect, but it avoids the chained procedure that these authors use. In the chained procedure the decision problems that participants are offered depend on their previous choices. With the choice list all participants face the same decision problems. Also, in contrast to chained procedures, the choice list is incentive compatible.

Participants make choices in one choice list for each prospect. That is, in total they made 40 choices. After the participants made all choices, one of these choices was randomly selected for real play for each participant. Depending on his decision in the selected choice problem, the participant received either the sure cash amount or played the prospect with a chance to win ETB 20.

Because most of our subjects had no formal education and many were illiterate, the instructions were given verbally in local language using posters as visual aids. All probabilities and randomizations were demonstrated using balls and dice, and no explicit reference to probabilities was given. Visual aids have been shown to improve the understanding of risks by participants without formal training in probability theory and were clearly necessary in our sample (Carlsson et al., 2004; Corso et al., 2001). The prospects and the betting tasks were demonstrated using the risky option by filling the bag with 5 white and 5 yellow balls. A subject chose a color by putting a ball of this color on the table. Next, a ball was randomly drawn. If the colors matched, the subject was paid ETB 20. The binary choices between the prospects and the sure amounts of money were presented to the participant by the experimenter one at a time. The experimenter filled out the choice list according to the participant's preference in each choice. 
Control group. As a comparison standard, we use data from an experiment where the above decision task was conducted with undergraduate university students at a Dutch university (Trautmann et al., 2008b, experiment 4). The tasks and randomizations were identical to the Ethiopian sample apart from the following. The prize was $€ 50$ for the two prospects for the student sample, and 2 of 79 students were randomly selected for real play of their choices. Students received written instructions and filled out the choice lists by themselves.

\section{Experimental results}

\subsection{Risk and ambiguity attitudes}

Risk attitudes. The certainty equivalents for the risky prospect allow us to control for risk attitude in the measurement of ambiguity below. Risk attitudes are of independent interest, however, and we report the data here. In this subsection we assume expected utility with power utility and report constant relative risk aversion (CRRA) coefficients. With the simple two-outcome gain prospects studied here the results do not change if we assume linear utility and interpret risk aversion in terms of probability weighting as in rank dependent utility and prospect theory ${ }^{5}$.

The median coefficient of relative risk aversion in the Ethiopian sample is $\rho=0.73$, which is significantly larger than the median of $\rho=0.34$ in the Dutch student sample (MannWhitney $\mathrm{U}$ test, $\mathrm{z}=4.391, \mathrm{p}<0.01)$. Table 1 shows that the percentage of risk neutral and seeking participants is very similar in both groups, but that among the peasants there are very few mildly and medium risk averse. In particular, 41 of the 92 participants in Ethiopia preferred the sure payoff in all choices. The table also includes the distribution of individual CRRA parameters as estimated by Holt and Laury (2002) for a sample of U.S. students using real payoffs up to $\$ 77$ (see Holt and Laury, 2002, Table 3, last column). Their study indicates more risk aversion than the Dutch study and the distribution is closer to the Ethiopian sample. However, there are still only about $40 \%$ highly risk averse participants in Holt and Laury (2002) compared to the $60 \%$ highly risk averse in our Ethiopian case.

\footnotetext{
${ }^{5}$ Because we have only one indifference point (one certainty equivalent for one risky prospect), we would have to restrict the analysis to single-parameter probability weighting functions. Econometric estimation of more flexible weighting functions requires more information and therefore more complex elicitation procedures (Abdellaoui, 2000; Bleichrodt and Pinto, 2000; Viscusi and Evans, 2006).
} 
Table 1. Distribution of constant relative risk aversion parameters in Ethiopian peasants versus university student samples

\begin{tabular}{|l|l|l|l|l|}
\hline & $\begin{array}{l}\text { Risk neutral/ } \\
\text { loving }\end{array}$ & $\begin{array}{l}\text { Mildly risk } \\
\text { averse }\end{array}$ & Risk averse & $\begin{array}{l}\text { Highly risk } \\
\text { averse }\end{array}$ \\
\hline & $\rho \leq 0.15$ & $0.15<\rho \leq 0.41$ & $0.41<\rho \leq 0.68$ & $\rho>0.68$ \\
\hline Ethiopian farmers (n=92) & $22 \%$ & $11 \%$ & $10 \%$ & $58 \%$ \\
\hline $\begin{array}{l}\text { Dutch students (n=79) } \\
\text { Trautmann et al. (2008b) }\end{array}$ & $19 \%$ & $35 \%$ & $44 \%$ & $1 \%$ \\
\hline $\begin{array}{l}\text { U.S. students (n=93) } \\
\text { Holt and Laury (2002) }\end{array}$ & $19 \%$ & $19 \%$ & $23 \%$ & $39 \%$ \\
\hline
\end{tabular}

Notes. Numbers are rounded. Identical tasks in Ethiopia and the Netherlands. Holt and Laury (2002, Table 3, last column) use a slightly different task with all choice options involving only non-degenerated gambles.

Ambiguity attitudes. In our experiment the individual ambiguity attitudes are determined by the participant's certainty equivalents for the risky and the ambiguous prospect. As a measure of ambiguity aversion, we employ the value

$\frac{\text { certainty equivalent risky prospect - certainty equivalent ambiguous prospect }}{\text { certainty equivalent risky prospect + certainty equivalent ambiguous prospect }}$

This measure ranges from -1 (ambiguity loving) to 0 (ambiguity neutrality) to 1 (ambiguity averse). The larger the difference between the two certainty equivalents, the stronger the ambiguity attitude, controlling for the absolute level of risk attitude. The normalization controls for the fact that a difference of ETB 2 weighs more heavily for a subject who is very risk averse (e.g. certainty equivalent risky prospect of ETB 4) than for a subject who is relatively risk neutral (e.g. certainty equivalent risky prospect of ETB 9).

Because of the strong risk aversion in the Ethiopian sample we have 41 participants who revealed the lowest feasible certainty equivalent for the risky prospect. These participants could not reveal ambiguity aversion by having a lower certainty equivalent for ambiguous and we exclude them from the analysis. Ambiguity attitudes did not differ between the Ethiopian peasants and the Dutch students (Mann-Whitney U tests, $\mathrm{z}=1.535$, $\mathrm{p}>0.1$ ). In both samples we find clear ambiguity aversion (Wilcoxon tests, ps<0.01). Table 2 shows the distribution of ambiguity attitudes in the Ethiopian and the Dutch samples based on certainty equivalents, and for three comparison studies. Roca et al. (2006) gave British university students a simple choice between betting on the color in the risky or the ambiguous Ellsberg two-color urn as in our experiment. The distribution of ambiguity aversion in their 
basic experiment replicates standard findings in the literature and is similar to our results in Ethiopia. ${ }^{6}$

Table 2. Ambiguity attitudes in Ethiopian peasants versus comparison samples

\begin{tabular}{|l|l|l|l|l|}
\hline & $\begin{array}{l}\text { Ambiguity } \\
\text { seeking } \\
\text { neutral }\end{array}$ & $\begin{array}{l}\text { Ambiguity } \\
\text { averse }\end{array}$ & $\begin{array}{l}\text { Ambiguity } \\
\text { Method }\end{array}$ \\
\hline Ethiopian farmers (n=51) & $20 \%$ & $24 \%$ & $57 \%$ & $\begin{array}{l}\text { CE, gains, } \\
\text { real incentives }\end{array}$ \\
\hline $\begin{array}{l}\text { Dutch students (n=79) } \\
\text { Trautmann et al. (2008b) }\end{array}$ & $15 \%$ & $43 \%$ & $42 \%$ & $\begin{array}{l}\text { CE, gains, } \\
\text { real incentives }\end{array}$ \\
\hline $\begin{array}{l}\text { British students (n=72) } \\
\text { Roca et al. (2006) }\end{array}$ & $39 \%$ & n.a. & $61 \%$ & $\begin{array}{l}\text { Choice, gains, } \\
\text { hypothetical }\end{array}$ \\
\hline $\begin{array}{l}\text { Business owners (n=130) } \\
\text { Chesson and Viscusi (2003) }\end{array}$ & $56 \%$ & n.a. & $44 \%$ & $\begin{array}{l}\text { Choice, losses, } \\
\text { hypothetical }\end{array}$ \\
\hline $\begin{array}{l}\text { Dutch students (n=39) } \\
\text { Keren and Gerritsen (1999) }\end{array}$ & $3 \%$ & $46 \%$ & $51 \%$ & $\begin{array}{l}\text { WTP, gains, } \\
\text { hypothetical }\end{array}$ \\
\hline
\end{tabular}

Notes. Numbers rounded. Identical tasks in Ethiopia and the Netherlands. Roca et al., (2006), Table 1, control; Chesson and Viscusi (2003), Table III, panel B; Keren and Gerritsen (1999), Table 4, panel b.

The two other studies illustrate the effect of two design features on ambiguity attitude and show that the induced differences are much stronger than the differences between the different samples of participants in the first three rows of the table. Chesson and Viscusi (2003) study ambiguity attitude for loss prospects among business owners in the U.S. Clearly, there is more ambiguity seeking in their study compared to our study, consistent with findings for losses in the literature (Cohen et al., 1985; DiMauro and Maffioletti, 1996; Ho et al., 2002; Hogarth and Kunreuther, 1985; Kahn and Sarin, 1988). Keren and Gerritsen (1999) elicited Dutch university students' willingness-to-pay (WTP) for the risky and the ambiguous Ellsberg two-color urn. They find clear ambiguity aversion and almost none of the subjects were willing to pay more for the ambiguous option. ${ }^{7}$

\footnotetext{
${ }^{6}$ Note that $8(20 \%)$ of the 41 subjects with extreme risk aversion that we excluded were ambiguity seeking, while the remaining subjects were ambiguity neutral or averse. This is similar to the distribution for the unconstrained subjects in Table 2.

${ }^{7}$ Trautmann et al. (2008b) illustrate this strong effect of WTP elicitation on ambiguity attitudes and provide a model that suggests that WTP overestimates ambiguity aversion.
} 


\subsection{Effects of demographic variables}

Before the experiment was conducted, the Ethiopian participants were interviewed on a number of socio-economic background variables beyond the normally observed age and gender for student samples. The descriptive statistics are summarized in Table 3.

Table 3. Socio-Economic background variables for the Ethiopian sample $(n=92)$.

\begin{tabular}{llll}
\hline \hline Personal & Mean & Min & Max \\
Age in years & & & \\
Female & 43 & 22 & 80 \\
Poor health (yes=1) & $51 \%$ & 0 & 1 \\
Family & $28 \%$ & 0 & 1 \\
Married (yes=1) & & & \\
Household size (not including respondent) & $81 \%$ & 0 & 1 \\
Number of dependent children & 4.59 & 0 & 11 \\
Economic & 2.58 & 0 & 6 \\
Land size (in timads; 1 hectare $\approx 4$ timads) & & & \\
Monthly consumption per household (ETB) & 1.84 & 1 & 4 \\
\hline \hline
\end{tabular}

We regress the risk and ambiguity attitudes on this set of explanatory variables. For risk attitude we avoid dependence on expected utility assumptions by using the pure certainty multiplied by -1 as an index or risk aversion. In the regressions we control for censoring of our measures because a sizable fraction of participants revealed the lowest possible certainty equivalent. Thus, we use a Tobit model for our analysis of risk attitude. We also test whether socio-economic variables explain the presence of extreme risk attitudes by including a Probit regression for dummy variable that assumes the value of 1 if the certainty equivalent is censored at 1 , and 0 otherwise. For ambiguity attitude we apply OLS regressions for the measure described in section 2.1 because there is no censoring of ambiguity attitude. Regression results are shown in Table 4. Positive parameter values in the regressions imply increasing risk or ambiguity aversion, or increasing likelihood to show extreme level of risk aversion respectively. Marginal effects are reported for the probit regression. 
Table 4. Regression analysis for risk and ambiguity aversion for the Ethiopian sample.

\begin{tabular}{|c|c|c|c|}
\hline Explanatory $\begin{array}{c}\text { Dependent } \\
\text { variable } \\
\text { variable }\end{array}$ & $\begin{array}{l}\text { Risk } \\
\text { Aversion } \\
\text { (Tobit) }\end{array}$ & $\begin{array}{l}\text { Extreme risk } \\
\text { aversion (Probit) }\end{array}$ & $\begin{array}{l}\text { Ambiguity } \\
\text { aversion (OLS) }\end{array}$ \\
\hline Age & $\begin{array}{l}-.562 \\
(.573)\end{array}$ & $\begin{array}{l}-.045 \\
(.031)\end{array}$ & $\begin{array}{l}-.03 \\
(.026)\end{array}$ \\
\hline Age squared & $\begin{array}{l}.004 \\
(.006)\end{array}$ & $\begin{array}{l}.001 \\
(.001)\end{array}$ & $\begin{array}{l}.0002 \\
(.0002)\end{array}$ \\
\hline Female & $\begin{array}{l}-2.941 \\
(2.557)\end{array}$ & $\begin{array}{c}-.089 \\
(.142)\end{array}$ & $\begin{array}{l}-.129 \\
(.146)\end{array}$ \\
\hline Poor Health & $\begin{array}{l}5.265^{*} \\
(2.822)\end{array}$ & $\begin{array}{r}.344 * * \\
(.133)\end{array}$ & $\begin{array}{l}.339 * * \\
(.154)\end{array}$ \\
\hline Married & $\begin{array}{l}-3.887 \\
(3.43)\end{array}$ & $\begin{array}{l}-.174 \\
(.183)\end{array}$ & $\begin{array}{l}-.433 * * \\
(.167)\end{array}$ \\
\hline Household size & $\begin{array}{r}1.574 * \\
(.836)\end{array}$ & $\begin{array}{l}.102 * * \\
(.044)\end{array}$ & $\begin{array}{l}.045 \\
(.062)\end{array}$ \\
\hline \# dependent children & $\begin{array}{l}-.886 \\
(1.006)\end{array}$ & $\begin{array}{l}-.029 \\
(.053)\end{array}$ & $\begin{array}{l}.029 \\
(.045)\end{array}$ \\
\hline Land size & $\begin{array}{l}-.192 \\
(1.203)\end{array}$ & $\begin{array}{l}-.007 \\
(.069)\end{array}$ & $\begin{array}{l}.092 \\
(.073)\end{array}$ \\
\hline Consumption & $\begin{array}{l}.0001 \\
(.002)\end{array}$ & $\begin{array}{l}.0001 \\
(.0001)\end{array}$ & $\begin{array}{l}.0001 \\
(.0001)\end{array}$ \\
\hline \# observations & 84 & 84 & 45 \\
\hline
\end{tabular}

Notes. $* *$, $*$ denote significance at the $5 \%$ and $10 \%$ level, standard errors in parenthesis (robust standard errors for OLS). Marginal effects are reported for the Probit regression.

The regression results show that poor health is related both to stronger risk aversion and stronger ambiguity aversion. In particular, for risk, the subjects with poor health status demonstrate extreme risk aversion. Apart from health effects, we find that household size increases risk aversion, while being married reduces ambiguity aversion. No other socioeconomic variables had an influence on uncertainty attitudes in our data.

To control for the possibility of nonlinear effects of the economic variables land and consumption we plotted uncertainty attitudes against these variables. If anything, for risk aversion these plots suggested an U-shaped relation for land size and a logarithmic shape for consumption. We included the nonlinear transformations in another set of regressions. The nonlinear effects were not significant and did not affect the above shown results. 


\section{Discussion}

Cross sample comparison. There has been much interest in cross cultural differences in attitudes towards uncertainty, and numerous studies have measured attitudes toward prospects with objectively known payoff distributions in developing countries and small scale societies (Binswanger, 1980; Bohnet et al., 2008; Kuznar, 2001; Yesuf and Bluffstone, 2007; Henrich and McElreath; Dillon and Scandizzo, 1978; Elamin and Rogers, 1992; Weber and Hsee, 1998). Most of these studies found a similar degree of risk aversion as those commonly found in student samples from developed countries. Henrich and McElreath (2002) showed that there can be significant differences between culturally diverse peasant societies, however. ${ }^{8}$ These authors also suggested the importance of cross cultural comparison of attitudes toward ambiguous prospects, when probabilities are unknown. In the real world ambiguity is ubiquitous, and farmers' preferences between traditional uncertain technologies with well-known payoff distributions and new technologies and crops with unknown risks are relevant to innovation and development.

We study risk and ambiguity attitude experimentally in a sample of poor Ethiopian peasants. The experiment uses real incentives and concrete visual representations of prospects in terms of differently colored balls in urns, without reference to probabilities. We compare the Ethiopian data to data from an experiment among Western university students using exactly the same decision task. Holding design features constant between groups is necessary to draw conclusions regarding cross cultural differences, especially when studying potentially volatile ambiguity attitudes (Bohnet et al., 2008; Kocher et al., 2008; Roth et al., 1991; Herrmann et al., 2008).

We find both risk aversion and ambiguity aversion for Ethiopian peasants. Risk aversion is stronger for the peasants than for the comparison student samples, and this effects is driven by extreme risk attitudes among the peasants. Comparing the distribution of risk attitudes with other findings from standard Western student populations shows, however, that variation is well within the range of the variation that would be expected across different experiments. In any case, the data support the view that strong risk aversion predominates among the farmers.

Ambiguity aversion did not differ between Ethiopian peasants and Dutch university students, and both groups show ambiguity aversion. Ambiguity attitudes in the samples

\footnotetext{
${ }^{8}$ Similarly, Bohnet et al. (2008) found evidence for social risk aversion (betrayal aversion) in the six countries contained in their study, but they also found clear differences in the strength of the aversion across these countries.
} 
considered in our study are also comparable to those reported in the literature for gains and choice elicitation. Contrasting our results with the results in the literature that use different framing (losses) or a different elicitation method (WTP) shows that slight differences in the experimental design can strongly affect ambiguity attitudes. This illustrates the importance of keeping design features constant when comparing ambiguity attitudes across different participant populations. Otherwise the effects of the elicitation method may wrongly be interpreted as sample differences in attitudes, possibly leading to wrong policy.

Effects of socio-economic variables. The finding of relatively high risk aversion for Ethiopian peasants compared to Western university students suggests a possible link between poverty and risk aversion. The explanation is not supported by the analysis of socio-economic background data, however. Neither land size (wealth) nor consumption (income) had any significant influence on risk attitudes. The absence of wealth effects on risk attitude is consistent with the results in Binswanger (1980), Henrich and McElreath (2002), and Booij and van de Kuilen (2009). Positive effects of wealth and income on risk tolerance have been found in Donkers et al. (2001) and Dohmen et al. (2005), however, and Barsky et al. (1997) find a U-shaped effect of wealth and income with first decreasing and then increasing risk tolerance. We tested for such U-shape relationship in our data set but did not find evidence for it.

Unlike many studies, we find no gender effect for risk attitude (Borghans et al., 2009; Donkers et al. 2001; Schubert et al., 1999). There is a clear effect of health status, with subjects in poor health being more risk averse. In particular, subjects in poor health show extreme risk aversion and therefore add to the observed differences with student samples. A similar effect is observed for household size, with subjects responsible for larger households being more risk averse.

There is little evidence yet on the effect of socio-economic variables on ambiguity attitude. Regressions analysis of our socio-economic data shows that, similar to the effect on risk attitude, poor health increases ambiguity aversion. Marriage reduces ambiguity aversion in our sample. No other effects are found. Consistent with findings in Borghans et al. (2009), there is no clear gender effect for ambiguity.

Poor health and uncertainty attitude. The lack of strong socio-economic effects on risk and ambiguity attitudes is largely consistent with the literature. Our finding of a strong effect of health is interesting in this respect. Most direct measurements of attitudes toward 
uncertainty about monetary payoffs in the economics literature do not account for health states or use subject pools with little variation in health status. Viscusi and Evans (1990) estimate utility functions for income explicitly accounting for health state, using the state dependent utility framework proposed by Zeckhauser (1970). They found reduced marginal utility of income in poor health states compared to full health. Our result of increased risk aversion under poor health can be explained within this framework by relatively flat utility functions under impaired health compared to good health. Our finding for increased ambiguity aversion for poor health cannot easily be explained within this state dependent utility framework, however.

The result is also consistent with temperance (Eeckhoudt et al., 1995; Eeckhoudt and Schlesinger, 2006): temperate decision makers dislike to assume more (independent) risks in situations in which they are already confronted with a risk. If poor health indicates situations of high health background risk, participants will be less willing to take an additional financial risk than in situations of low health risk, i.e., in good health. Again, the effects of poor health on ambiguity aversion do not simply follow from this framework either. The ambiguity effect would suggest that the precautionary motive of temperance becomes stronger in the case of risks for which the decision maker feels less competent.

Finally, note that the relatively high degree of risk aversion among the farmers, and especially the occurrence of extreme attitudes, might be driven by negative past experiences. Compared to decision makers in Western societies, for our Ethiopian small scale farmers poor outcomes resulting from risky decisions are arguably more severe. A poor harvest after switching to a promising new crop that turned out unsuitable for the local soils can threaten the existence of the family, in particular for those household heads in poor health.

\section{Conclusion}

Attitudes toward uncertainty are important factors in the analysis of economic problems and policy in developing countries. Risk-sharing, crop selection, and precautionary saving influence welfare in risky agricultural environments and are influenced by economic actors' attitudes toward risk (Dercon 1996; Jalan and Ravallion 2001; Kochar, 1999; Pan, 2008; Udry, 1994). Henrich and McElreath (2002) argue that apart from risk attitude also ambiguity attitude, that is, preferences toward prospects with unknown payoff distributions, 
may be important to development. Adoption of new technology and crops which involve unknown risks may depend more on ambiguity than on pure risk attitude.

Ambiguity aversion has been widely observed among Western university student samples, and theoretical models of ambiguity aversion have been proposed as explanations for market phenomena in developed economies (e.g. Mukerji and Tallon, 2001; Easley and O’Hara, 2008; Viscusi and Magat, 1992; Zeckhauser, 2006). In contrast to most findings in the literature, Henrich and McElreath (2002) reported positive attitudes toward ambiguity in their experiments with Chilean Mapuche peasants. They also found strong risk seeking for prospects with known probabilities. These authors argue that diverse cultural factors drive uncertainty attitudes and that ambiguity aversion might be specific to western student populations. In contrast, we find strong ambiguity and risk aversion in experimental decision tasks for our sample of Ethiopian peasants. Although consistent with the view that uncertainty attitudes depend on cultural factors, these results clearly show that ambiguity aversion is also observed in populations deviating on various dimensions from standard university student populations. This suggests that both risk and ambiguity attitude are important for economic decisions in poor agricultural societies, and that both attitudes should be considered in policies regarding the situation of the poor. 


\section{Appendix}

\section{A Choice list elicitation of certainty equivalents}

The choices were presented to the participants in increasing order of the sure amounts. In the example the certainty equivalent is calculated as the midpoint between the largest sure amount for which the participant chooses to play the gamble, and the smallest sure amount for which the participants chooses to take the sure cash. That is, the certainty equivalent of the risky prospect is ETB 6.5:

[1] Bet on a draw from white bag $\otimes$

[2] Bet on a draw from white bag

[3] Bet on a draw from white bag

[4] Bet on a draw from white bag

[5] Bet on a draw from white bag

[6] Bet on a draw from white bag

[7] Bet on a draw from white bag

[8] Bet on a draw from white bag

[9] Bet on a draw from white bag

[19] Bet on a draw from white bag

[20] Bet on a draw from white bag $\otimes$

$\otimes$

$\otimes$

$\otimes$

$\otimes$

$\otimes$

$\mathrm{O}$

$\mathrm{O}$

$\mathrm{O}$

$\mathrm{O}$

$\mathrm{O}$
O Receive 1 Birr for sure

O Receive 2 Birr for sure

O Receive 3 Birr for sure

O Receive 4 Birr for sure

O Receive 5 Birr for sure

O Receive 6 Birr for sure

$\otimes \quad$ Receive 7 Birr for sure

$\otimes \quad$ Receive 8 Birr for sure

$\otimes \quad$ Receive 9 Birr for sure

$\otimes \quad$ Receive 19 Birr for sure

$\otimes \quad$ Receive 20 Birr for sure

Participants were presented one choice list for each prospect (risky and ambiguous). One of the choices was randomly selected for payment and played according to the participant's choice.

\section{B Instructions for Ethiopian Participants}

Good morning (Good afternoon)! My name is X. I am here to play a game with you. Before we begin, I will explain the rules of the game. This is an individual exercise, so please do not talk. Please hold your questions until I have finished the explanations. In this game, you can make money. The money will be paid tomorrow by your teacher. How much money you make, depends to large extent on your decisions. Therefore, it is important that you understand the rules of the game. Please listen carefully. 
In the first part of the game, you can choose between drawing a ball from the black bag (show the bag) and have a chance to win 20 birr, or just receive a certain amount of money.

The drawing from the black bag will be conducted in the following way. We will fill the bag with 5 yellow and 5 white balls. (Fill the bag with balls and count aloud.) When it is my turn to draw a ball from the bag, I will draw one ball without looking. Before I draw a ball, I will pick a color-let us say white. If I pick a white ball from the bag, I will place a white ball on the desk. (Put a white ball on the desk.) If I draw a second white ball later, I will get 20 birr. If the ball is yellow, I will not get anything. (Draw a ball and announce the color.)

You will soon get an answer sheet, which looks like the one on the wall. When you play the game, I would like you, for each choice, to decide if you would like to draw a ball from the black bag (show the bag) or if you just want a certain amount of money. Of all the choices you make, only one of them will be played for real. Which choice will be played for real will be randomly determined by rolling a dice. For example, I will decide if I prefer to draw a ball from the black bag (show the bag) and have the possibility to win 20 birr or receive 1 birr for sure. If I prefer to draw from the bag (rather than getting 1 birr for sure), then I check this box on the left (point on the left box); otherwise, I check this box on the right (point at the right box).

In next choice, I also decide if I would like to draw a ball from the black bag or get a certain amount of money for sure. But, this time I will receive 2 birr for sure. As you can see, the amount in birr increases in the right column. (Point at the right column.) As long as I want to draw a ball from the black bag instead of getting a certain amount of money for sure, I check the left box (point at the left box). Assume that I prefer to draw a ball from the black bag, then I can check here (point at the left boxes in the second to last choice). But, in the last choice, I shall always check the right box (point) because it must be better to for sure get 20 birr than draw a ball from the black bag which might give me 20 birr.

Assume that I do not want to draw from the black bag at all, then in the first choice I choose to get the money for sure and continue with that for all choices (point at the right column). But, most likely, I will begin by choosing to draw from the black bag until the choice situation comes when I prefer to choose the for sure amount (show with a sweeping motion). When I have chosen the for sure amount, then I continue with that for the rest of the choice situations. If I prefer 1 birr for sure in the first choice situation, rather than drawing a ball from the black bag, then it is clear that in next choice situation, I will prefer 2 birr for sure over drawing a ball from the black bag.

Have everyone understood the rules of the game? (Leave time for questions.) 
The second part of our game is similar to the first, but there is one important difference: the black bag is now replaced by the white bag. (Show the bag.) Now you will decide if you would like to draw a ball from the white bag and have a chance to win 20 birr or if you would like to get a certain amount of money for sure.

The draw from the white bag is conducted in the following way. We have filled the white bag with white and yellow 10 balls. However, how many of there exist of each color is secret. Before I draw a ball, I will pick a color, exactly as before, and put the ball with the selected color on the desk. When it is my turn to draw a ball from the bag, I will draw one ball without looking. The only thing that differs the first part is that the black bag contains 5 white and 5 yellow balls (show the bag) while the white bag contains 10 balls, but the number of balls of each color is secret.

You will all get a second answer sheet, which looks like the poster on the wall. When you play the game, I would like you to decide, for each choice, if you want to draw a ball from the white bag or if you for sure would like a certain amount of money.

Have everyone understood the rules of the game? (Leave time for questions.)

Now I will explain how you will get your money. When everybody has made all their 20 choices (point at all choices), each of you will roll a 6-edged dice to decide whether the answer sheet with the black or white bag will be used. If the dice shows the numbers 1,2 , or 3 , then the answer sheet with the black bag will be used. If the dice shows the numbers 4,5 , or 6 , then the white bag will be used (show the dice). Then, you will roll a 20-edged dice to decide which of the 20 alternatives will be played (show the dice). The number shown will be the choice situation played for real.

First, I will throw the 6-edged dice (throw the dice). If I roll number 3, the answer sheet with the black bag is in play (point at poster with a black bag). Then, I will roll the 20edged dice to decide which choice situation on the answer sheet will played for real (throw the dice). If I roll number 5, the choice situation 5 in the black bag will be played for real (point at poster with a black bag and at choice situation 5). Now comes the most important part: if, in choice situation 5, I have chosen to draw from the black bag, then I must draw a ball from the black bag. If I guessed the correct color, I will win 20 birr, otherwise I will get nothing. Remember that the black bag contains 5 white and 5 yellow balls. If I have chosen to get a certain amount of money for sure, I will get 5 birr. If, for example, I roll number 5 when I roll the 6-edged dice, then the white bag is the valid one. If I then roll the 20 -edged dice and get number 11, choice situation 11 will be played (point at white bag and choice situation 11 on the poster). If I then draw a ball with the same color as I have guessed, I win 20 birr; otherwise I will get nothing. Remember that the white bag contains 10 balls, but you do not know how many balls are white and yellow. If I have chosen to get a certain amount of money for sure, I will get 11 birr. 
When you roll the two dice, you can get either of the 2 bags and any of the 20 choice situations. Therefore, you should carefully think about each choice: whether you would like to draw a ball from the bag or for sure get a certain amount of money.

Have everyone understood the rules of the game? (Leave time for questions.)

\section{References}

Abdellaoui, Mohammed (2000), Parameter-free elicitation of utility and probability weighting functions. Management Science 46 (11), 1497-1512.

Barsky, Robert B., F. Thomas Juster, Miles S. Kimball and Matthew D. Shapiro (1997). Preference Parameters and Behavioral Heterogeneity: An Experimental Approach in the Health and Retirement Study. Quarterly Journal of Economics 112, 537-579.

Binswanger, Hans P. (1980). Attitudes toward Risk: Experimental Measurement in Rural India. American Journal of Agricultural Economics 62, 395-407.

Bleichrodt, Han and Jose Luis Pinto (2000). A parameter-free elicitation of the probability weighting function in medical decision analysis. Management Science 46 (11), $1485-1496$.

Bohnet, Iris, Fiona Greig, Benedikt Hermann, and Richard Zeckhauser (2008). Evidence from Brazil, China, Oman, Switzerland, Turkey, and the United States. American Economic Review 98(1), 294-310.

Booij, Adam S. and Gijs van de Kuilen (2009). A Parameter-Free Analysis of the Utility of Money for the General Population under Prospect Theory. Journal of Economic Psychology, forthcoming.

Borghans, Lex, Bart H. H. Golsteyn, James J. Heckman, and Hub Meijers (2008). Gender Differences in Risk Aversion and Ambiguity Aversion. Journal of the European Economic Association, forthcoming.

Cabantous, Laure (2008). Ambiguity aversion in the field of insurance: Insurers' attitude to imprecise and conflicting probability estimates. Theory and Decision 62(3), 219-240.

Carlsson, Frederik, Olof Johansson-Stenman, and Peter Martinsson (2004). Is transport safety more valuable in the air? Journal of Risk and Uncertainty 28(2), 147-163.

Chesson, Harrell W. and W. Kip Viscusi (2003). Commonalities in time and ambiguity aversion for long-term risks. Theory and Decision 54, 57-71.

Chow, Claire C. and Rakesh K. Sarin (2002). Known, Unknown, and Unknowable Uncertainties. Theory and Decision 52, 127-138. 
Cohen, Michele., Jean-Yves Jaffray and Tanios Said (1985). Individual Behavior under Risk and Uncertainty: An Experimental Study. Theory and Decision 18, 203-328.

Corso, Phaedra, James K. Hammitt, and John D. Graham. (2001). Valuing Mortality-Risk Reduction: Using Visual Aids to Improve the Validity of Contingent Valuation. Journal of Risk and Uncertainty 23, 165-184.

Curley, Shawn P., J. Frank Yates and Richard A. Abrams (1986). Psychological Sources of Ambiguity Avoidance. Organizational Behavior and Human Decision Processes 38, 230-256.

Dercon, Stefan (1996). Risk, Crop Choice, and Savings: Evidence from Tanzania. Economic Development and Cultural Change 44, 485-513.

Dillon, John L. and Pasquale L. Scandizzo (1978). Risk attitudes of subsistence farmers in Northeast Brazil: A sampling approach. American Journal of Agricultural Economics 60: $425-435$.

Di Mauro, Carmela and Anna Maffioletti (1996). An Experimental Investigation of the Impact of Ambiguity on the Valuation of Self-Insurance and Self-Protection. Journal of Risk and Uncertainty 13, 53-71.

Dohmen, Thomas, Armin Falk, David Huffman, Uwe Sunde, Jürgen Schupp and Gert G. Wagner (2005). Individual Risk Attitudes: New Evidence from a Large, Representative, Experimentally-Validated Survey. Working Paper, IZA.

Donkers, Bas, Bertrand Melenberg and Arthur van Soest (2001). Estimating Risk Attitudes Using Lotteries: A Large Sample Approach. Journal of Risk and Uncertainty 22, $165-195$.

Easley, David and Maureen O'Hara (2008). Ambiguity and Non-participation: The Role of Regulation, Review of Financial Studies, forthcoming.

Eeckhoudt, L., C. Gollier, and T. Schneider (1995). Risk Aversion, Prudence, and Temperance: A Unified Approach. Economics Letters 48. 331-336.

Eeckhoudt, L. and H. Schlesinger (2006). Putting risk at its proper place. American Economic Review 96, 280-289.

Elamin, Eltighani M. and LeRoy F. Rogers (1992). Estimation and use of risk aversion coefficients for traditional dryland agriculture in western Sudan. Agricultural Economics 7, 155-166.

Ellsberg, Daniel (1961). Risk, Ambiguity and the Savage Axioms. Quarterly Journal of Economics 75, 643-669. 
Feder, G. (1980), Farm Size, Risk Aversion and the Adoption of New Technology under Uncertainty, Oxford Economic Papers 32, 263-283

Feder, G., R. Just and D. Zilberman (1985), Adoption of agricultural innovations indeveloping countries: a survey, Economic Development and Cultural Change, 33, 255298.

Fox, Craig R. and Amos Tversky (1995). Ambiguity Aversion and Comparative Ignorance. Quarterly Journal of Economics 110, 585-603.

Halevy, Y. (2007). Ellsberg Revisited: An Experimental Study. Econometrica 75, 503-536.

Heath, Chip and Amos Tversky (1991). Preference and Belief: Ambiguity and Competence in Choice and Uncertainty. Journal of Risk and Uncertainty 4, 5-28.

Henrich, Joseph and Richard McElreath (2002). Are peasants risk-averse decision makers? Current Anthropology 43(1), 172-181.

Herrmann, Benedikt, Christian Thöni and Simon Gächter (2008). Antisocial Punishment Across Societies. Science 319, 1362-1367.

Ho, Joanna L. Y., L. Robin Keller, and Pamela Keltyka (2002). Effects of Outcome and Probabilistic Ambiguity on Managerial Choices. Journal of Risk and Uncertainty 24(1), $47-74$.

Hogarth, Robin M. and Howard Kunreuther (1985). Ambiguity and Insurance Decisions. American Economic Review 75(2), 386-390.

Holt, Charles A. and Susan K. Laury (2002). Risk Aversion and Incentive Effects. American Economic Review 92, 1644-1655.

Jalan, Jyotsna and Martin Ravallion (2001). Behavioral Responses to Risk in Rural China. Journal of Development Economics 66, 23-49.

Kahn, Barbara E. and Rakesh K. Sarin (1988). Modeling Ambiguity in Decisions under Uncertainty. Journal of Consumer Research 15, 265-272.

Kebede, Y. (1992). Risk Behaviour and Agricultural Technologies: The Case of Producers in Central Highlands of Ethiopia. Quarterly Journal of International Agriculture 31, 269284.

Keren, Gideon B. and Léonie E. M. Gerritsen (1999). On the Robustness and Possible Accounts of Ambiguity Aversion. Acta Psychologica 103, 149-172.

Kocher, Martin G., Todd Cherry, Stephan Kroll, Robert J. Netzer, and Matthias Sutter (2008). Conditional cooperation on three continents. Economics Letters, forthcoming. 
Kochar, Anjini (1999). Smoothing Consumption by Smoothing Income: Hours-of-Work Responses to Idiosyncratic Agricultural Shocks in Rural India. Review of Economics and Statistics 81, 50-61.

Kuznar, Lawrence A. (2001). Risk sensitivity and value among Andean pastoralists: Measures, models, and empirical tests. Current Anthropology 42(3), 432-440.

Maffioletti, Anna and Michele Santoni (2005). Do trade union leaders violate subjective expected utility? Some insights from experimental data. Theory and Decision 59, 207-253.

Maffioletti, Anna and Ulrich Schmidt (2008). The effect of the elicitation method on ambiguity attitudes. Working paper, Kiel University.

Mukerji, Sujoy and Jean.-Marc Tallon (2001). Ambiguity Aversion and Incompleteness of Financial Markets. Review of Economic Studies 68, 883-904.

Pan, Lei (2008). Risk pooling through transfers in Rural Ethiopia. Economic Development and Cultural Change, forthcoming.

Roca, Merce, Robin M. Hogarth and A. John Maule (2006). Ambiguity Seeking as a Result of the Status Quo Bias. Journal of Risk and Uncertainty 32, 175-194.

Roth, Alvin E., Vesna Prasnikar, Masahiro Okuno-Fujiwara, and Shmuel Zamir (1991). Bargaining and Market Behavior in Jerusalem, Ljubljana, Pittsburgh, and Tokyo: An Experimental Study. American Economic Review 81(5), 1068-1095.

Sarin, R. K. and M. Weber (1993). Effects of Ambiguity in Market Experiments. Management Science 39, 602-615.

Savage, Leonard J. (1954). The Foundations of Statistics. Wiley, New York.

Schubert, Renate, M. Brown, Matthias Gysler and Hans-Wolfgang Brachinger (1999). Financial Decision-Making: Are Women Really More Risk-Averse. American Economic Review 89, 381-385.

Trautmann, Stefan T., Ferdinand M. Vieider and Peter P. Wakker (2008a). Causes of Ambiguity Aversion: Known versus Unknown Preferences. Journal of Risk and Uncertainty 36, 225-243.

Trautmann, Stefan T., Ferdinand M. Vieider and Peter P. Wakker (2008b). Preference reversals for ambiguity aversion. Working Paper, Erasmus University.

Udry, Christopher (1994). 1994. Risk and Insurance in a Rural Credit Market: An Empirical Investigation in Northern Nigeria. Review of Economic Studies 61, 495-526.

Viscusi, W. Kip and Harrell W. Chesson (1999). Hopes and fears: The conflicting effects of risk ambiguity. Theory and Decision 47, 153-178. 
Viscusi, W. Kip and William N. Evans (1990). Utility functions that depend on health status: Estimates and economic implications. American Economic Review 80, 353-274.

Viscusi, W. Kip and William N. Evans (2006). Behavioral Probabilities. Journal of Risk and Uncertainty 32(1), 5-15.

Viscusi, W. Kip and Wesley A. Magat (1992). Bayesian decisions with ambiguous belief aversion. Journal of Risk and Uncertainty 5, 371-387

Weber, Elke U. and Christopher Hsee (1998). Cross-Cultural Differences in Risk Perception, but Cross-Cultural Similarities in Attitudes towards Perceived Risk. Management Science 44 (9), 1205-1217.

Yesuf, Mahmud and Randy Bluffstone (2007). Risk Aversion in Low Income Countries. Working Paper, IFPRI.

Zeckhauser, Richard J. (1970). Medical Insurance: A Case Study of the Tradoff between Risk Spreading and Appropriate Incentives. Journal of Economic Theory 2, 10-26.

Zeckhauser, Richard J. (2006). Investing in the Unknown and Unknowable. Capitalism and Society 1, Article 5. 